\title{
59. MAGNETIC PROPERTIES AND PALEOMAGNETISM OF VOLCANIC ROCKS AND INTERLAYERED SEDIMENTS FROM THE JAPAN SEA (ODP LEG 127) ${ }^{1}$
}

\author{
L. Vigliotti ${ }^{2}$
}

\begin{abstract}
Measurements of natural remanent magnetization (NRM), initial susceptibility (K), anisotropy of magnetic susceptibility, frequency dependent susceptibility (Xfd), and viscous remanent magnetization (VRM) are reported from volcanic rocks recovered during ODP Leg 127 in the Japan Sea. The results indicate a significant difference between the basalts drilled in the Yamato Basin (Site 794 and 797) and in the Japan Basin (Site 795). The Koenigsberger ratios (Q) show very low values in the Yamato Basin attesting that the remanence is not dominant over the induced magnetization. This evidence could explain why no magnetic anomaly pattern has been recognized in this basin.

Experiments of VRM acquisition and decay show that both the processes are multistage with the acquisition process proceeding more rapidly and deviates more from a $\log (t)$ law than the corresponding decay. The sediments interlayered with the basalts in the acoustic basement of the Yamato Basin show processes of remagnetization related to the emplacement of the dikes. Temperatures of heating between $200^{\circ}$ and $250^{\circ} \mathrm{C}$ were estimated from the different unblocking temperatures of the two components of magnetization.
\end{abstract}

\section{INTRODUCTION}

One of the aims of Ocean Drilling Program (ODP) Leg 127 was to drill the basement of the Japan Sea. The acoustic basement of the basin was successfully recovered from three sites: 794, 795, 797. This study reports the magnetic properties and the paleomagnetic measurements of 100 basalt samples recovered at Hole 794C (Yamato basin, 24 samples), Hole 795B (Japan basin, 19 samples), and Hole 797C (Yamato basin, 57 samples). At Sites 794 and 797 the basalts were interlayered with sediments, and paleomagnetic measurements were also carried out on a small collection of sedimentary samples.

The magnetic properties of rocks are useful indicators of the composition, concentration, and alteration state of magnetic minerals; such studies examine the sources of the remanence and its petrogenetic significance. In this paper the magnetic properties of the rock are used to investigate its relationships with modes and times of emplacement, and its implications for the magnetic anomalies in the Japan Sea. The magnetic parameters included in the measurements are: intensity and direction of natural remanent magnetization (NRM), acquisition and decay of viscous remanent magnetization (VRM), initial susceptibility (K), frequency dependent susceptibility (Xfd), and anisotropy of magnetic susceptibility (AMS).

The basement drilled at Site 794 consists of a total of $33.5 \mathrm{~m}$ of dolerite of tholeiitic composition and $1.5 \mathrm{~m}$ of welded tuffs. The $32 \mathrm{~m}$ of igneous rocks are divided into six units, each representing separate intrusive sills (Tamaki, Pisciotto, Allan, et al., 1990); the tuffs divide Unit V from Unit VI. Most of the igneous rocks are highly altered, and their ages are unknown.

At Site 795 , about $80 \mathrm{~m}$ of basalt, basaltic andesites, and basaltic breccias were drilled in the acoustic basement. The recovered $17.6 \mathrm{~m}$ of volcanic rocks are moderately to highly altered and vesicular; on the basis of texture and mineralogy, they are divided into three units of unknown ages.

Basalt, alkali basalt, hawaiite, and dolerite interlayered with sediments represent the acoustic basement cored in Hole 797C. A total of

\footnotetext{
' Tamaki, K., Suyehiro, K., Allan, J., McWilliams, M., et al., 1992. Proc. ODP, Sci. Results, 127/128, Pt. 2: College Station, TX (Ocean Drilling Program).

${ }^{2}$ Istituto di Geologia Marina-CNR, 40127 Bologna, Italy.
}

$347 \mathrm{~m}$ of this basement was cored and $140 \mathrm{~m}$ of igneous rocks and sediments was recovered. The lithology of the interlayered sediments varies with increasing depth, from sandstone to siltstone, and claystone. The $80 \mathrm{~m}$ of the recovered igneous rocks basically includes two broad and overlapping groups containing 21 separate units on the basis of contact relations, intervening sedimentary rocks, composition, and texture (Tamaki, Pisciotto, Allan, et al., 1990). The upper group consists of Units 1,2, and 4 and lacks chilled margins which mark the lower group of units consisting of Units 3 and 5-21. The upper group is considered to be representative of lava flows and is predominantly massive while group 2 is highly fractured and brecciated.

\section{SAMPLES AND LABORATORY PROCEDURES}

Sedimentary samples were collected from the working half of the core sections, cutting cubic samples $\left(7 \mathrm{~cm}^{3}\right)$ with a spatula. More consolidated sediments were drilled with a double-blade press diamond saw. Cylindrical igneous samples $(2.54 \mathrm{~cm}$ diameter) were drilled with a diamond drill bit.

Paleomagnetic measurements were carried out in the Paleomagnetic Lab of the Istituto di Geologia Marina of CNR of Bologna (Italy). The anisotropy of magnetic susceptibility (AMS) was measured with a Jelinek Kappa bridge in the Paleomagnetic Lab of the Università di Torino (Italy). The natural remanent magnetization (NRM) of the sediments was measured with a Jelinek JR-4 spinner magnetometer, while for igneous rocks a Schonstedt spinner magnetometer was used. Few samples were studied on board the JOIDES Resolution using a Molspin spinner magnetometer. The frequency dependence magnetic susceptibility $\left(\mathrm{X}_{\mathrm{fd}}(\%)=100 \times\left(\mathrm{K}_{\mathrm{Lf}}-\mathrm{K}_{\mathrm{Hf}}\right) / \mathrm{K}_{\mathrm{Lf}}\right)$ was measured with a Bartington Instrument magnetic susceptibility meter (model M.S.2) which allows measurements in two frequencies: $0.47 \mathrm{~Hz}$ (Lf) and $4.7 \mathrm{~Hz}$ (Hf). The Koenigsberger ratio (Q) was calculated assuming a local field value of $45000 \mathrm{nT}$.

Acquisition and decay of viscous remanent magnetization (VRM) were carried out on the original remanence of the rock. The whole collection of igneous rocks was arbitrarily oriented and in the laboratory under the Earth Magnetic Field (about 45000 nT), and the NRM measured at intervals, spaced approximately logarithmically, for $1376 \mathrm{hr}$. On the basis of the results of the VRM acquisition, 20 samples were selected and stored in a magnetic shield with a low field of about $70 \mathrm{nT}$. The NRM was measured on an interval of time lasting $7176 \mathrm{hr}$. 


\section{RESULTS}

The magnetic properties for each specimen of igneous rock are listed in Tables 1, 2, and 3, for Site 794, 795 and 797, respectively, in order of increasing depth in each hole. Figure 1 shows typical orthogonal plots of samples demagnetized by thermal and alternating field methods. Magnetic properties of some sediments from Site 797 are discussed in the paper of Torii et al. (this volume). In this chapter the distribution of the data in the three sites will be presented.

Table 1. Magnetic properties of igneous rocks recovered at Site 794.

\begin{tabular}{|c|c|c|c|c|c|c|c|c|}
\hline $\begin{array}{l}\text { Depth } \\
\text { (mbsf) }\end{array}$ & K & NRM & $\begin{array}{c}\text { VRM/ } \\
\text { NRM \% }\end{array}$ & VRM & $X_{\mathrm{fd}}$ & F & $K_{1} / K_{3}$ & Q \\
\hline 542.72 & 35981 & 5470 & 8.60 & 470 & & 1.005 & 1.005 & 4.10 \\
\hline 560.54 & 41720 & 645 & 9.60 & 62 & 1.33 & 1.012 & 1.020 & 0.42 \\
\hline 565.67 & 37210 & 589 & 81.7 & 481 & 1.27 & 1.024 & 1.038 & 0.43 \\
\hline 573.03 & 49320 & 3470 & 19.3 & 670 & 2.19 & 1.031 & 1.047 & 1.91 \\
\hline 582.29 & 34820 & 306 & 206 & 630 & 2.23 & 1.040 & 1.045 & 0.24 \\
\hline 586.17 & 43030 & 1040 & 60.6 & 630 & & 1.045 & 1.057 & 0.66 \\
\hline 587.04 & 32720 & 889 & 39.5 & 351 & 1.01 & 1.036 & 1.053 & 0.74 \\
\hline 588.10 & 38850 & 898 & 70.4 & 632 & 2.93 & 1.022 & 1.036 & 0.63 \\
\hline 592.16 & 39960 & 1190 & 15.1 & 180 & 0.86 & 1.011 & 1.013 & 0.81 \\
\hline 601.95 & 26650 & 228 & 194 & 444 & 1.18 & 1.018 & 1.027 & 0.23 \\
\hline 602.51 & 25803 & & & & 1.14 & 1.005 & 1.007 & \\
\hline 605.71 & 30970 & 1660 & 7.20 & 120 & 1.16 & 1.012 & 1.022 & 1.46 \\
\hline 606.98 & 32800 & 736 & 56.3 & 414 & 2.12 & 1.008 & 1.012 & 0.61 \\
\hline 615.50 & 32463 & 801 & 39.0 & 312 & 1.10 & 1.031 & 1.035 & 0.67 \\
\hline 623.44 & 49820 & 3050 & 30.0 & 930 & 0.93 & 1.009 & 1.012 & 1.66 \\
\hline 624.63 & 43360 & 882 & 61.0 & 538 & 1.05 & 1.015 & 1.019 & 0.55 \\
\hline 627.37 & 34107 & 1970 & 4.60 & 90 & 0.67 & 1.004 & 1.006 & 1.57 \\
\hline 628.79 & 38311 & 996 & 31.5 & 314 & 1.33 & 1.017 & 1.020 & 0.71 \\
\hline 634.98 & 35866 & 3250 & 11.4 & 370 & 0.48 & 1.004 & 1.006 & 2.46 \\
\hline 635.62 & 50560 & 2490 & 4.40 & 110 & & 1.006 & 1.010 & 1.34 \\
\hline 635.87 & 54849 & 1070 & 16.8 & 180 & 0.65 & 1.007 & 1.010 & 0.53 \\
\hline 636.80 & 41560 & & & & 0.77 & 1.008 & 1.009 & \\
\hline 640.43 & 28910 & 648 & 60.5 & 392 & 1.32 & 1.012 & 1.016 & 0.61 \\
\hline 645.93 & 39758 & 6350 & 5.70 & 360 & 0.80 & 1.017 & 1.020 & 4.34 \\
\hline Mean & 38303 & 1756 & 46.9 & 395 & 1.26 & & 1.21 & \\
\hline
\end{tabular}

Symbols: K, magnetic susceptibility $\left(\times 10^{-6}\right.$ S.I. Units). NRM, intensity of natural remanent magnetization $(\mathrm{mA} / \mathrm{m})$. VRM/NRM \%, ratio of the viscous remanent magnetization acquired after $1376 \mathrm{hr}$ with respect to the initial NRM. VRM, difference between VRM acquired after $1376 \mathrm{hr}$ and the initial NRM; values are expressed in $\mathrm{mA} / \mathrm{m}$. $\mathrm{X}_{\mathrm{ff}}$, frequency dependence susceptibility (\%). F, parameter of emplacement mode (Ellwood 1975 ). $\mathrm{K}_{1} / \mathrm{K}_{3}$, ratio between the maximun and the minimum susceptibility. Q, Koenigsberger ratio.

Table 2. Magnetic properties of igneous rocks recovered at Site 795. Symbols as in Table 1 .

\begin{tabular}{rrrrrrrr}
\hline $\begin{array}{r}\text { Depth } \\
\text { (mbsf) }\end{array}$ & NRM & VRM & $\begin{array}{r}\text { VRM/ } \\
\text { NRM \% }\end{array}$ & F & K & Q & X $_{\text {fd }}$ \\
\hline 684.33 & 188 & 170 & 90.4 & 1.007 & 23383 & 0.2 & 0.57 \\
693.71 & 129 & 172 & 133.3 & 1.010 & 23111 & 0.5 & 1.02 \\
702.94 & 154 & 72 & 46.8 & 1.008 & 23449 & 0.2 & 0.81 \\
705.08 & 17100 & 300 & 1.8 & & 28870 & 16.1 & 1.7 \\
712.88 & 15900 & 600 & 3.8 & 1.012 & 29093 & 14.9 & 1.97 \\
722.74 & 17600 & 700 & 4.0 & 1.015 & 31504 & 15.2 & 2.32 \\
724.08 & 8990 & 480 & 5.3 & 1.025 & 28943 & 8.4 & 1.91 \\
725.57 & 20400 & 1100 & 5.4 & 1.012 & 32159 & 17.2 & \\
726.90 & 5640 & 410 & 7.3 & 1.014 & 34199 & 4.5 & 1.23 \\
727.59 & 5650 & 390 & 6.9 & 1.020 & 35909 & 4.3 & 1.42 \\
732.05 & 21000 & 800 & 3.8 & 1.012 & 19957 & 28.6 & 4.24 \\
733.50 & 37200 & 1600 & 4.3 & 1.015 & 25063 & 40.3 & 2.57 \\
741.82 & 18900 & 900 & 4.8 & 1.009 & 24116 & 21.3 & 2.48 \\
741.98 & 94 & 14 & 15.3 & & 930 & 2.7 & 2.15 \\
742.32 & 18 & 2 & 11.5 & 1.001 & 391 & 1.3 & \\
742.69 & 15000 & 600 & 4.0 & 1.016 & 14576 & 28.0 & 3.57 \\
751.78 & 827 & 200 & 41.3 & 1.001 & 280 & 63.6 & \\
752.23 & 16700 & 500 & 3.0 & 1.012 & 19070 & 23.8 & \\
753.07 & 9240 & 650 & 7.0 & 1.014 & 31360 & 8.0 & \\
Mean & 11091 & 508 & 20 & 1.012 & 22440 & 15.7 & 1.99 \\
\hline
\end{tabular}

Table 3. Magnetic properties of igneous rocks recovered at Site 797. Symbols as in Table 1.

\begin{tabular}{|c|c|c|c|c|c|c|c|}
\hline $\begin{array}{l}\text { Depth } \\
\text { (mbsf) }\end{array}$ & K & $\mathrm{K}_{1} / \mathrm{K}_{3}$ & NRM & $\begin{array}{c}\text { VRM } \\
\text { NRM (\%) }\end{array}$ & $\mathrm{X}_{\mathrm{fd}}$ & Q & $\mathrm{F}$ \\
\hline 553.66 & 15690 & 1.026 & 475 & 72.0 & 0.66 & 0.82 & 1.022 \\
\hline 561.08 & 23443 & 1.059 & & & 1.41 & & 1.044 \\
\hline 561.70 & 24877 & 1.031 & 528 & 108.3 & 0.88 & 0.58 & 1.020 \\
\hline 562.37 & 28012 & 1.033 & 494 & 91.9 & 0.61 & 0.48 & 1.026 \\
\hline 570.39 & 20817 & 1.009 & 1070 & 24.2 & 0.59 & 1.40 & 1.005 \\
\hline 572.49 & 29470 & 1.033 & 1460 & 15.8 & 1.35 & 1.35 & 1.025 \\
\hline 573.47 & 28334 & I.008 & 422 & 89.8 & 0.93 & 0.40 & 1.006 \\
\hline 590.39 & 36330 & 1.020 & 336 & 192.6 & 0.64 & 0.25 & 1.016 \\
\hline 592.35 & 19410 & 1.028 & 1400 & 20.7 & 2.19 & 1.96 & 1.023 \\
\hline 594.95 & 26203 & 1.030 & 862 & 40.4 & 1.22 & 0.89 & 1.023 \\
\hline 599.17 & 29746 & 1.005 & 738 & 47.7 & 1.16 & 0.67 & 1.004 \\
\hline 609.33 & 10779 & 1.040 & 1280 & 3.1 & 0.57 & 3.23 & 1.026 \\
\hline 618.16 & 29149 & 1.031 & 445 & 80.7 & 1.00 & 0.41 & 1.017 \\
\hline 620.02 & 31658 & 1.029 & 885 & 52.5 & 0.68 & 0.76 & 1.027 \\
\hline 621.37 & 33810 & 1.032 & & & 2.02 & & 1.023 \\
\hline 627.77 & 25350 & 1.082 & 897 & 48.3 & 1.81 & 0.96 & 1.073 \\
\hline 629.10 & 21749 & 1.007 & 3660 & 8.2 & & 5.01 & 1.006 \\
\hline 637.53 & 40980 & 1.054 & 3570 & 11.8 & 1.63 & 2.37 & 1.043 \\
\hline 646.70 & 31589 & 1.032 & 779 & 36.1 & 0.76 & 0.67 & 1.031 \\
\hline 648.74 & 23616 & 1.022 & 724 & 19.5 & 0.93 & 0.83 & 1.019 \\
\hline 656.54 & 27210 & 1.061 & 553 & 80.3 & 2.36 & 0.55 & 1.045 \\
\hline 657.67 & 24210 & 1.124 & 729 & 44.0 & 0.82 & & 1.100 \\
\hline 660.77 & 20420 & 1.194 & 5240 & 20.2 & 2.26 & 6.97 & 1.147 \\
\hline 669.61 & 25522 & 1.023 & 753 & 30.3 & 1.05 & 0.80 & 1.019 \\
\hline 676.23 & 17478 & 1.067 & 200 & 83.5 & 1.22 & 0.31 & 1.045 \\
\hline 678.73 & 10814 & 1.027 & 110 & 93.6 & 0.98 & 0.28 & 1.016 \\
\hline 682.50 & 17438 & 1.117 & 1670 & 9.0 & 2.86 & 2.60 & 1.087 \\
\hline 682.99 & 16065 & 1.042 & 1180 & 20.4 & 1.16 & 1.66 & 1.039 \\
\hline 685.30 & 15225 & 1.007 & 710 & 15.8 & 0.54 & 1.27 & 1.006 \\
\hline 704.46 & 34390 & 1.076 & & & & & 1.064 \\
\hline 708.60 & 31730 & 1.235 & 611 & 88.2 & 3.08 & 0.52 & 1.186 \\
\hline 713.07 & 28250 & 1.120 & 2740 & 25.2 & & 2.64 & 1.097 \\
\hline 724.37 & 154110 & 1.017 & 2980 & 29.5 & 2.12 & 0.53 & 1.011 \\
\hline 725.70 & 61076 & 1.025 & 1060 & 43.4 & 0.67 & 0.47 & 1.080 \\
\hline 733.35 & 76300 & 1.003 & 686 & 125.9 & 0.64 & 0.24 & 1.002 \\
\hline 733.68 & 93610 & 1.021 & 737 & 90.0 & 0.75 & 0.21 & 1.016 \\
\hline 734.80 & 75460 & 1.019 & 1030 & 61.2 & 0.70 & 0.37 & 1.017 \\
\hline 743.30 & 101930 & 1.035 & 1120 & 83.0 & 0.86 & 0.30 & 1.029 \\
\hline 743.85 & 80590 & 1.026 & 1700 & 22.9 & 1.87 & 0.57 & 1.019 \\
\hline 745.07 & 96080 & 1.019 & 1460 & 35.6 & 1.21 & 0.41 & 1.012 \\
\hline 754.44 & 93740 & 1.010 & 1440 & 50.7 & 0.86 & 0.42 & 1.010 \\
\hline 758.69 & 70173 & 1.014 & 1570 & 31.8 & 0.64 & 0.61 & 1.009 \\
\hline 765.72 & 77230 & 1.046 & 2100 & 15.7 & 1.34 & 0.74 & 1.036 \\
\hline 769.20 & 87500 & 1.010 & 1100 & 94.5 & 0.99 & 0.34 & 1.008 \\
\hline 773.33 & 73090 & 1.020 & 15100 & 12.6 & & 5.61 & 1.012 \\
\hline 774.37 & 81230 & 1.011 & 1830 & 32.8 & 0.93 & 0.61 & 1.010 \\
\hline 781.78 & 76260 & 1.024 & 5840 & 3.8 & 0.55 & 2.08 & 1.016 \\
\hline 785.37 & 56260 & 1.013 & & & 0.59 & & 1.010 \\
\hline 806.99 & 45503 & 1.036 & 1510 & 4.6 & 0.74 & 0.90 & 1.024 \\
\hline 852.92 & 40735 & 1.049 & 1270 & 18.1 & 0.74 & 0.85 & 1.030 \\
\hline 881.63 & 43207 & 1.023 & 190 & 431 & 0.46 & 0.12 & 1.021 \\
\hline 883.70 & 50174 & 1.026 & 573 & 60.6 & 0.50 & 0.31 & 1.026 \\
\hline 884.84 & 52480 & 1.036 & 545 & 58.2 & 0.42 & 0.28 & 1.030 \\
\hline 885.45 & 839 & 1.003 & 13 & 5.4 & 0.42 & & 1.002 \\
\hline 891.21 & 38190 & 1.025 & 556 & 50.0 & 0.50 & 0.40 & 1.018 \\
\hline 892.76 & 35750 & 1.049 & 722 & 49.3 & 1.28 & 0.55 & 1.043 \\
\hline 894.96 & 28290 & 1.046 & 760 & 23.7 & 0.77 & 0.73 & 1.036 \\
\hline Mean & 43677 & & 1546 & 54.9 & 1.09 & 1.14 & \\
\hline
\end{tabular}

\section{Site 794}

The NRM intensities $(\mathrm{Jr})$, plotted downhole together with the magnetic susceptibility and the Koenigsberger ratio (Q) (Fig. 2) range from 228 to $6350 \mathrm{~mA} / \mathrm{m}$ without any trend, but with the two higher values at the top and bottom of the section. The mean value of $1756 \mathrm{~mA} / \mathrm{m}$ is within the range of the oceanic basalts. The magnetic susceptibility $(\mathrm{K})$ exhibited constant values around a mean value of $38303 \times 10^{-6}$ S.I. units. With these results for $\mathrm{Jr}$ and 
$127-794 \mathrm{~B}-26 \mathrm{R}-\mathrm{CC},(15-17 \mathrm{~cm})$
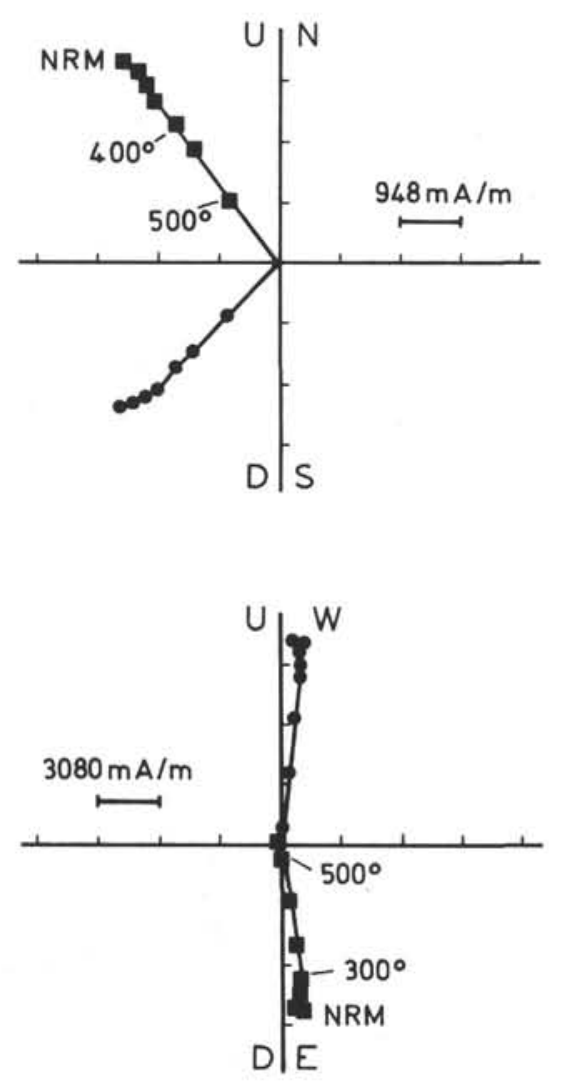

$127-795 B-41 R-1,93-95 \mathrm{~cm}$
$127-794 C-4 R-4,28-30 c m$
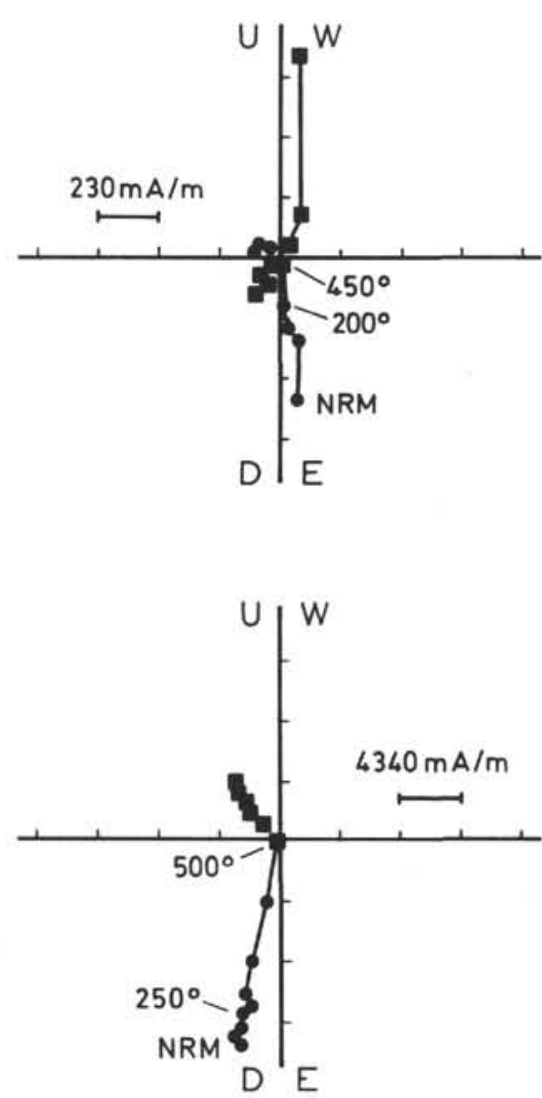

$127-795 B-38 R-3,77-79 c m$
$127-794 \mathrm{C}-10 \mathrm{R}-1,64-66 \mathrm{~cm}$
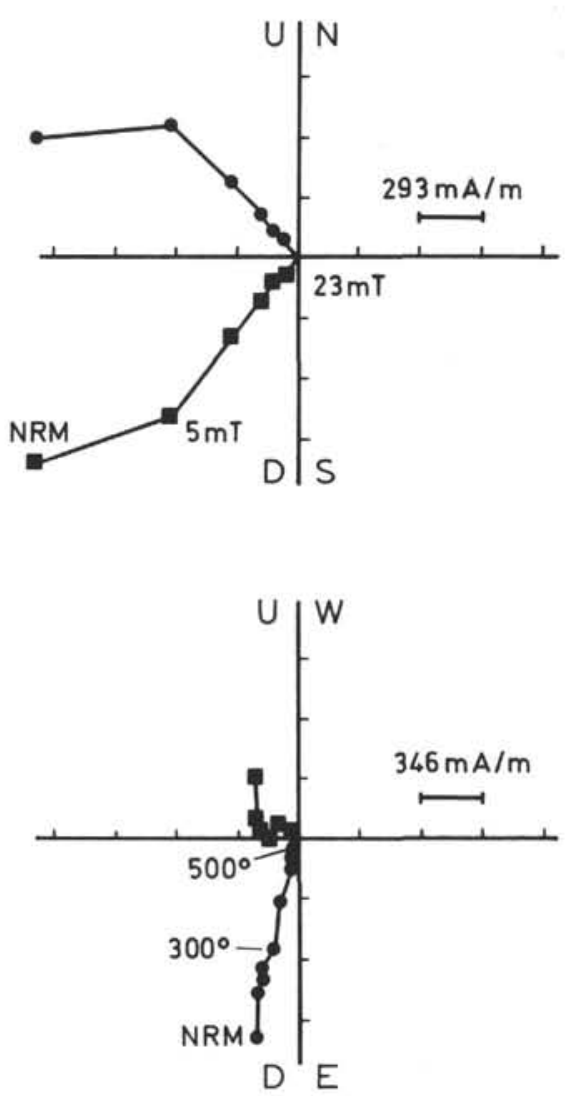

$127-797 C-10 R-2,116-118 \mathrm{~cm}$
$127-794 \mathrm{C}-12 \mathrm{R}-1,132-134 \mathrm{~cm}$
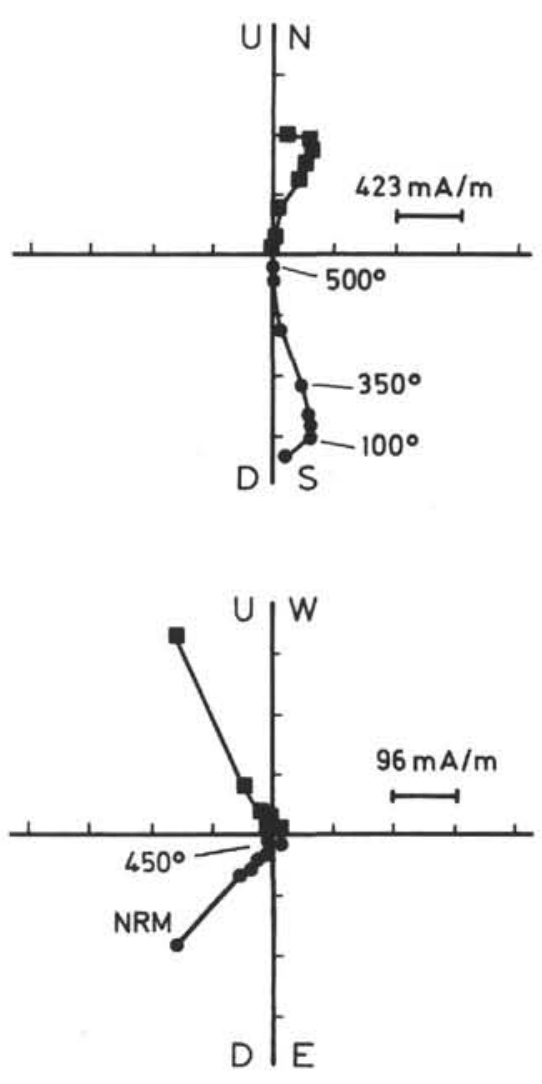

$127-797 \mathrm{C}-24 \mathrm{R}-1,46-48 \mathrm{~cm}$

Figure 1. Examples of vector demagnetization diagrams from igneous rocks. Square: horizontal plane. Dots: vertical plane. Horizontal orientation is arbitrary. 
$\mathrm{K}$, the distribution of the Koenigsberger ratio resembles that of the NRM and it is noteworthy that, although the mean value for $\mathrm{Q}$ is 1.2 , most of the samples had a value $<1$. All the samples showed to be very susceptible to acquisition of a VRM. The ratio VRM/NRM, which is an expression of the potential seriousness of the effect of VRM on the sample, varies from $4.4 \%$ to $206 \%$ with a mean value of $46.9 \%$ (Table 1). The values of the frequency dependent susceptibility $\left(\mathrm{X}_{\mathrm{fd}}\right)$ in most of the samples is more than $1 \%$ with a mean value of $1.26 \%$. The anisotropy of magnetic susceptibility (AMS) is weak, with the ratio $K_{1} / K_{3}$, commonly a measure of the degree of anisotropy, variable from 1.005 to 1.057 . In order to distinguish the emplacement mode of basalts, Elwood (1975) defined a parameter $\mathrm{F}\left(\mathrm{F}^{2}=\mathrm{K}_{1} 2 /\left(\mathrm{K}_{2} \times \mathrm{K}_{3}\right)\right)$ which separates intrusives $(\mathrm{F}>1.040)$ from extrusives $(\mathrm{F}<1.040)$ with $80 \%$ confidence. Although all the recovered igneous rocks are considered sills, only two dolerite samples from Unit 2 exhibited values of $F>1.040$. A plot of the parameter $F$ as function of depth is shown in Figure 3A.

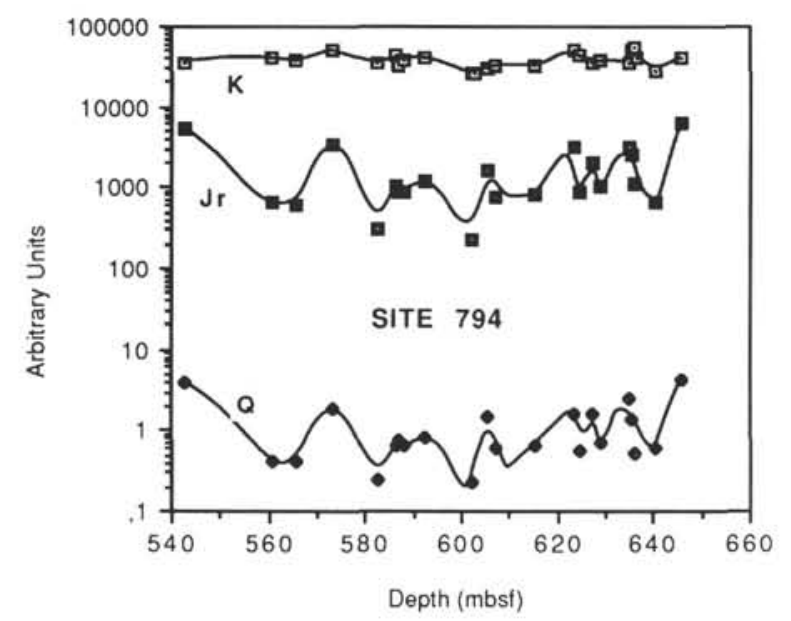

Figure 2. NRM intensity, magnetic susceptibility (K), and Koenigsberger ratio (Q) plotted vs. depth. Jr is expressed in $\mathrm{mA} / \mathrm{m} ; \mathrm{K}$ in $10^{-6} \mathrm{SI}$ Units.

Alternating field (AF) and thermal demagnetization were carried out on the basalts recovered from the basement of Site 794 . The median destructive field of the rock is below $10 \mathrm{mT}$ as can be expected from their VRM. The paleomagnetic record shows differences not only between the lithologic units, but even from core to core, suggesting different units from a paleomagnetic point of view. One sample (127-794B-26R-CC, 15-17 cm) from the first unit yielded a clear direction of normal polarity (Fig. 1), contrasting with the negative inclinations evidenced by the overlying black mudstone. The basalts recovered within the upper 11 cores from Hole 794C (560.0-629.2 mbsf) mostly exhibited a reversed polarity. This polarity was completely overprinted by a secondary component of normal polarity in the first six cores. This overprint, very probably the result of the present field on the VRM of the rock, was successfully removed by AF demagnetization with peak-field of $10-15 \mathrm{mT}$, or thermal treatment with temperatures above $300^{\circ}$ (Fig. 1). From Core 127-794C-7R through Core 127$794 \mathrm{C}-11 \mathrm{R}$, only the primary magnetization was observed. Two samples deviated from this picture: Sample 127-794C-3R-1, $103-105 \mathrm{~cm}$, and Sample 127-794C-8R-2, 38-40 cm. Both these samples exhibited a normal polarity, but while the latter belongs to a small piece that could have been rotated in the core, the polarity of the former is confirmed by the result obtained from an adjacent sample demagnetized on the ship. The stronger NRM intensity observed in the samples could give credit to a possible different
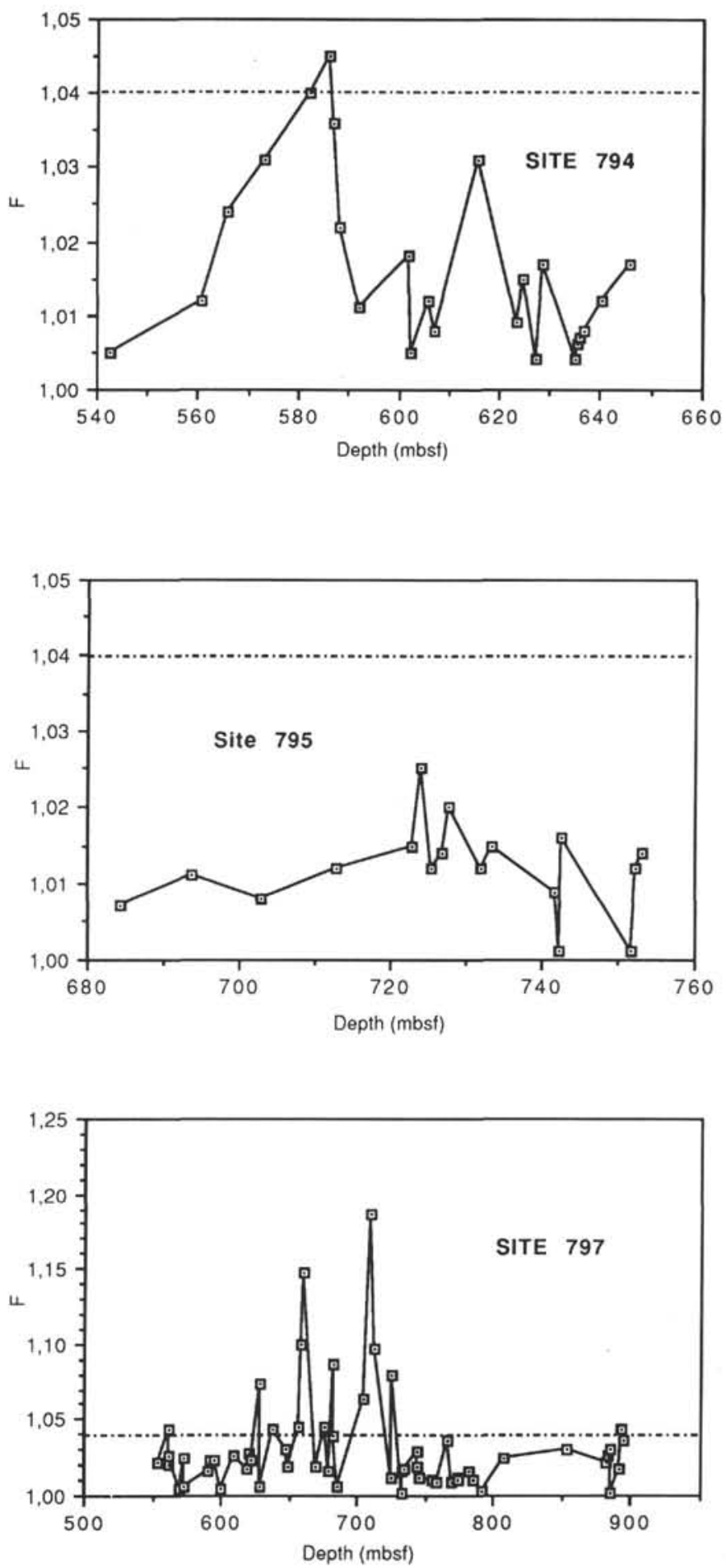

Figure 3. Parameter F as function of depth in the basalts drilled in the Japan Sea. Dotted line separates intrusives $(F>1.040)$ from extrusives $(F<1.040)$ emplacement (Ellwood 1975).

age for this sill. The inclination appears systematically shallower than the expected value of $56^{\circ}$ and in a few cases exceeds the value of $30^{\circ}-35^{\circ}$. The last two cores drilled at Hole $794 \mathrm{C}$ had a stable magnetization vector of normal polarity with consistent inclinations of about $60^{\circ}$. The same polarity was observed in the tuff dividing the last two units. 


\section{Site 795}

Site 795 is the only site drilled in the Japan Basin which reached the acoustic basement. Basaltic samples were studied only from the lithological units 1 and 3 while no samples were studied from the very small Unit 2 (703.3-704 mbsf) which probably is only an highly altered part of Unit 1 (Tamaki, Pisciotto, Allan, et al., 1990). Magnetic properties show clearly differences between the two units as can be seen in Figure 4 which summarize the results for the basalts drilled from Hole $795 \mathrm{~B}$. The magnetic susceptibility $(\mathrm{K})$ is mostly constant along the section (mean value: $22,440 \times 10^{-6}$ S.I. units) except few very altered specimens from the lower part of Unit 3 which is brecciated and is considered a subunit. The intensity of the NRM, the Koenigsberger ratio $(\mathrm{Q})$, and the ratio between VRM and NRM are very different between the two units. Unit 1 is characterized by an intensity of remanence (mean: $157 \mathrm{~mA} / \mathrm{m}$ ) which is about two orders of magnitude less than the NRM of Unit 3 (mean: $13,141 \mathrm{~mA} / \mathrm{m}$ ). The induced magnetization appears predominant over the remanence ( $Q$ mean: 0.3 ) in the upper unit, while in the Unit 3 the remanence is predominant (Q mean: 18.5). Moreover, the VRM of the upper unit is significant with a mean value of $90 \%$ for the ratio VRM/NRM, while the lower unit had only a few percent of viscosity (mean value of VRM/NRM\% $=5.6$ ). The frequency dependence susceptibility $\left(\mathrm{X}_{\mathrm{fd}}\right)$ tends to increase from Unit 1 (mean: 0.8 ) to Unit 3 (mean: 2.32). Optical observations suggest that the grain size of the magnetic minerals is different in the two units with finer grains in the lower unit. The anisotropy of magnetic susceptibility (AMS) is weak with the parameter $\mathrm{F}$ well below the value of 1.040 (Fig. 3B).

Demagnetizations of samples from this site (Fig. 1) confirmed the

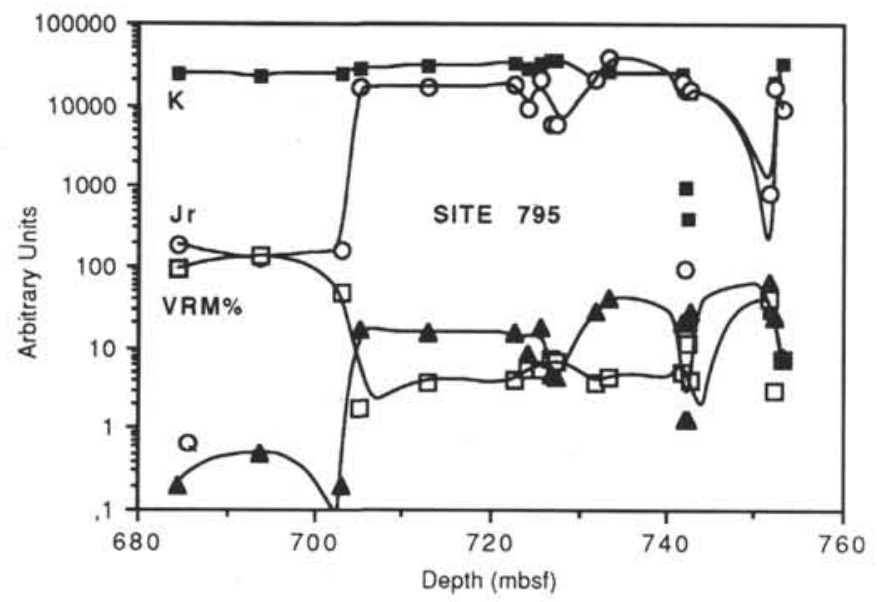

Figure 4. Magnetic susceptibility (K), NRM intensity, VRM/NRM\%, and Koenigsberger ratio (Q) of igneous rocks recovered at Site 795 plotted vs. depth. Values as in Table 1.

normal polarities obtained on board, except two samples which exhibited negative inclinations. One belong to Section 127-795B36R-1 and another one to Section 127-795B-41R-1. Probably the two samples were misoriented during the sampling, however, it must be noted that the former exhibited a normal polarity at the measure of the NRM and the direction changed drastically with AF peak field of only $5 \mathrm{mT}$. However, it is preferred to interpret all the basalts as normally magnetized.

\section{Site 797}

NRM intensities ( $\mathrm{Jr}$ ) and magnetic susceptibility (K) divide the sequence into three groups as showed by the downhole plots of Figure $5 \mathrm{~A}$ and $5 \mathrm{~B}$. The first group includes the first 16 cores which
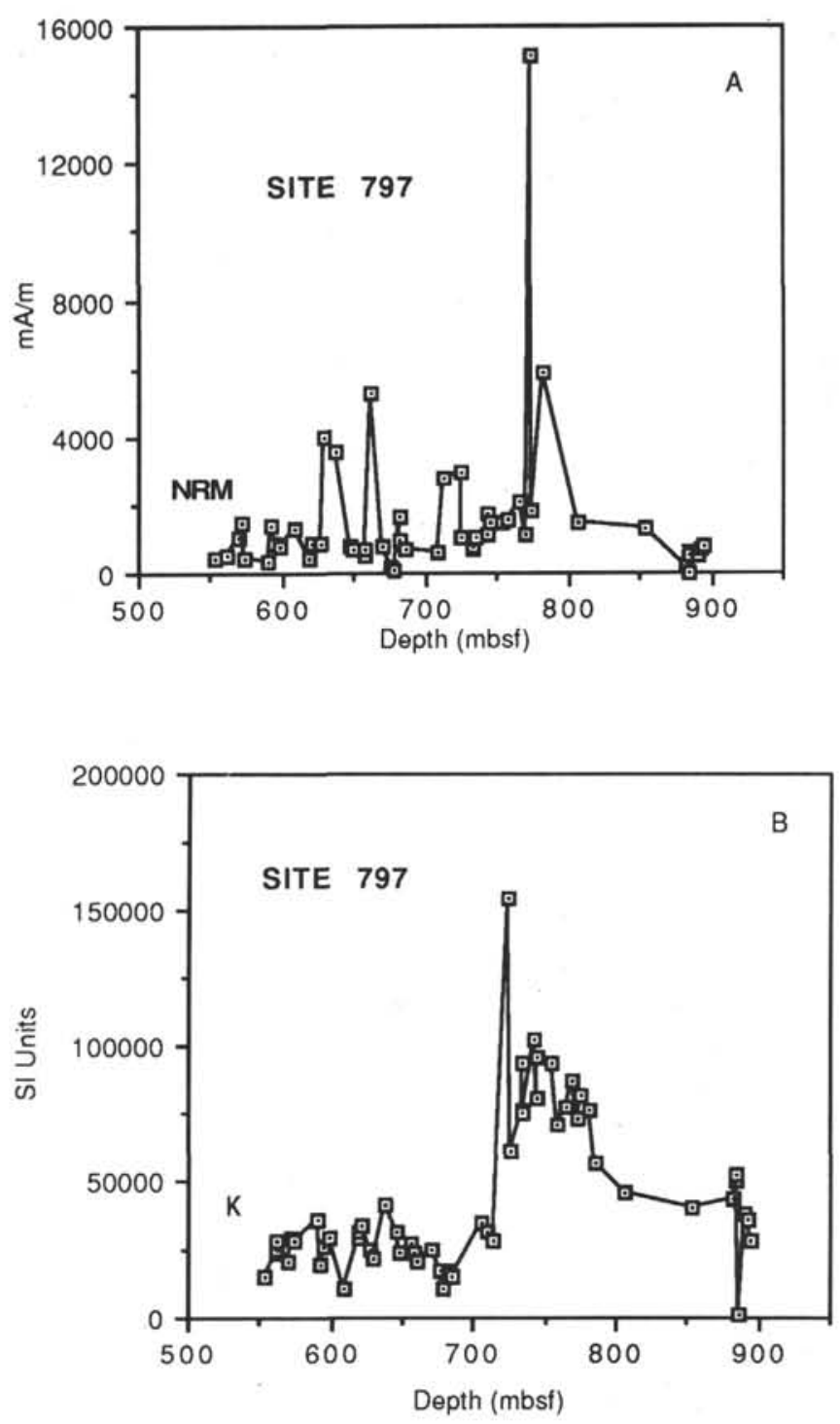

Figure 5. NRM intensity (A) and magnetic susceptibility (B) plotted vs. depth.

recovered igneous rocks (from Core 127-797C-8R through -24R; 550.9-713.6 mbsf; representing nine lithologic units) characterized by an intensity of magnetization that in most of the cases is below $10^{3} \mathrm{~mA} / \mathrm{m}$ (mean $1190 \mathrm{~mA} / \mathrm{m}$ ) and a magnetic susceptibility in the range $10-41 \times 10^{-3}$ S.I. units (mean $24,993 \times 10^{-6}$ S.I. units). The second group is represented by the basalts recovered from Cores $127-797 \mathrm{C}$ 26R through -36R (lithologic units 10-18; from 723.2 to 814.4 mbsf) with higher $\mathrm{Jr}$ (mean: $2579 \mathrm{~mA} / \mathrm{m}$ ) and $\mathrm{K}$ (mean: 82,361 S.I. units). The last three cores drilled into the basement (852.4-895.6 mbsf) which represents three lithologic units are characterized by lower NRM intensities (mean: $579 \mathrm{~mA} / \mathrm{m}$ ), by a mean value of susceptibility of $36,208 \times 10^{-6}$ S.I. units) and by a different polarity with respect to the upper units. The Koenigsberger ratio (Q), with the exception of few samples, is systematically below 1 as can be seen in the plot of Figure 6, indicating that the induced magnetization play an important role on the magnetic anomalies. Similar to Site 794 , the basalts from Site 797 exhibited a high VRM with a mean value for the ratio VRM/NRM\% of about $55 \%$. The frequency dependent susceptibility $\left(\mathrm{X}_{\mathrm{fd}}\right)$ had a mean value of $1.09 \%$. The anisotropy of magnetic susceptibility (AMS) is variable, and the parameter F is above the value which defines intrusive emplacement mode $(\mathrm{F}>1.040)$ only in the $25 \%$ of the samples (Fig. $3 \mathrm{C}$ ). Nevertheless, the majority of the 


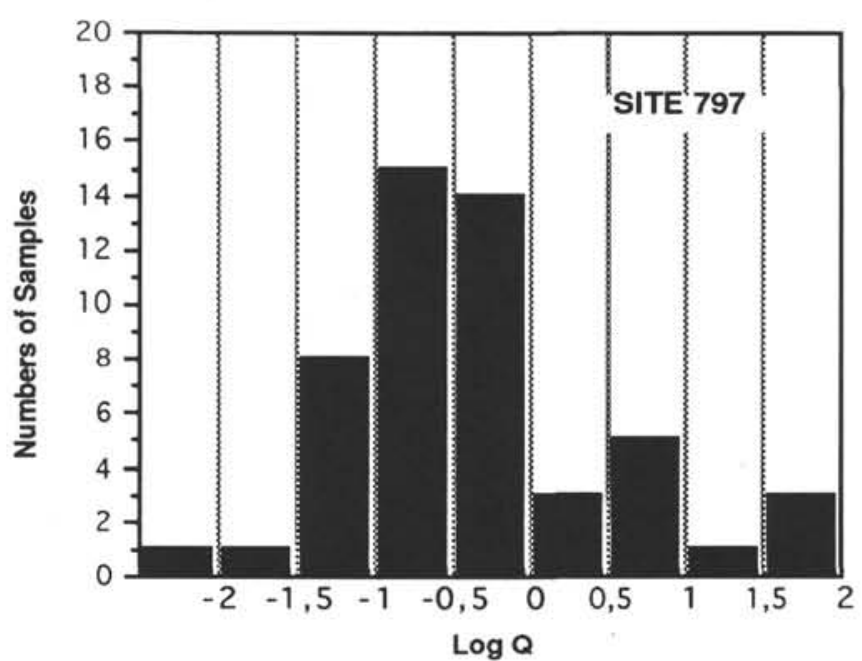

Figure 6. Histogram showing a log-normal distribution of the Koenigsberger ratio $(Q)$ values.

samples are clearly representative of sill, or dikes, as testified by the chilled margins. Most of the samples with a significant AMS belong to the basalts collected from Units 5-10.

Twenty-six specimens, that is at least one for each lithological unit, were demagnetized using both $\mathrm{AF}$ ( 22 samples) and thermal (4 samples) treatment. The basalts from the upper 18 units (from Core 127-797C-8R through Core -36R) exhibited consistently normal polarity while negative inclinations, mostly overprinted by a normal polarity, mark the samples belonging to the last three units. Two examples of vector demagnetization diagrams are shown in Figure 1.
The intrusion of the basaltic sills appears to have strongly affected the interlayered sediments that in many case exhibited remagnetization clearly due to the emplacement of the sills. Whole core measurements, on the archive halves of the cores, carried out on-board, exhibited a long normal polarity for the sediments interbedded with the basalts of the upper 12 units until Section 127-797C-30R-2 at 755.5 mbsf. These sediments represent lithostratigraphic Units V and VI. Thermal demagnetization of discrete samples collected from Unit VI changed dramatically this configuration. The samples showed a strong overprint that in several cases could be only partially removed, but the change of directions during the cleaning follow a great circle clearly indicating a reverse polarity. An example is reported in Figure 7. The sediments of lithostratigraphic Unit VI below 755.5 mbsf, from Core 127-797C-30R to Core 127-797C-37R still yield an overprint of normal polarity, but it could be easily removed (Fig. 8). Both thermal and AF cleaning were effective in isolating the primary direction of the sediment. Sedimentological evidence suggests that the sediments recovered with these cores are finer grained silty claystone. It is noteworthy that the two vectors of primary and secondary component were exactly opposite each other, so during thermal cleaning the intensity of the remanence increased, reaching in one sample (127-797C-37R-2, 116-118 cm), at $200^{\circ} \mathrm{C}$, a value of $376 \%$ with respect to the NRM intensity (Fig. 9). The darker colored claystone recovered with Core $127-797 \mathrm{C}-41 \mathrm{R}$ again exhibited a complex paleomagnetic record with a normal polarity that probably is of secondary origin. Even thermal demagnetization was ineffective in resolving the direction of a sample collected from this claystone. The direction changed during progressive demagnetization, but a negative polarity was obtained only at $480^{\circ} \mathrm{C}$ when the sample is viscous and the susceptibility increases. The reason of this overprint cannot be related to the emplacement of the overlying sill which also shows negative inclinations with an overprint of normal polarity.

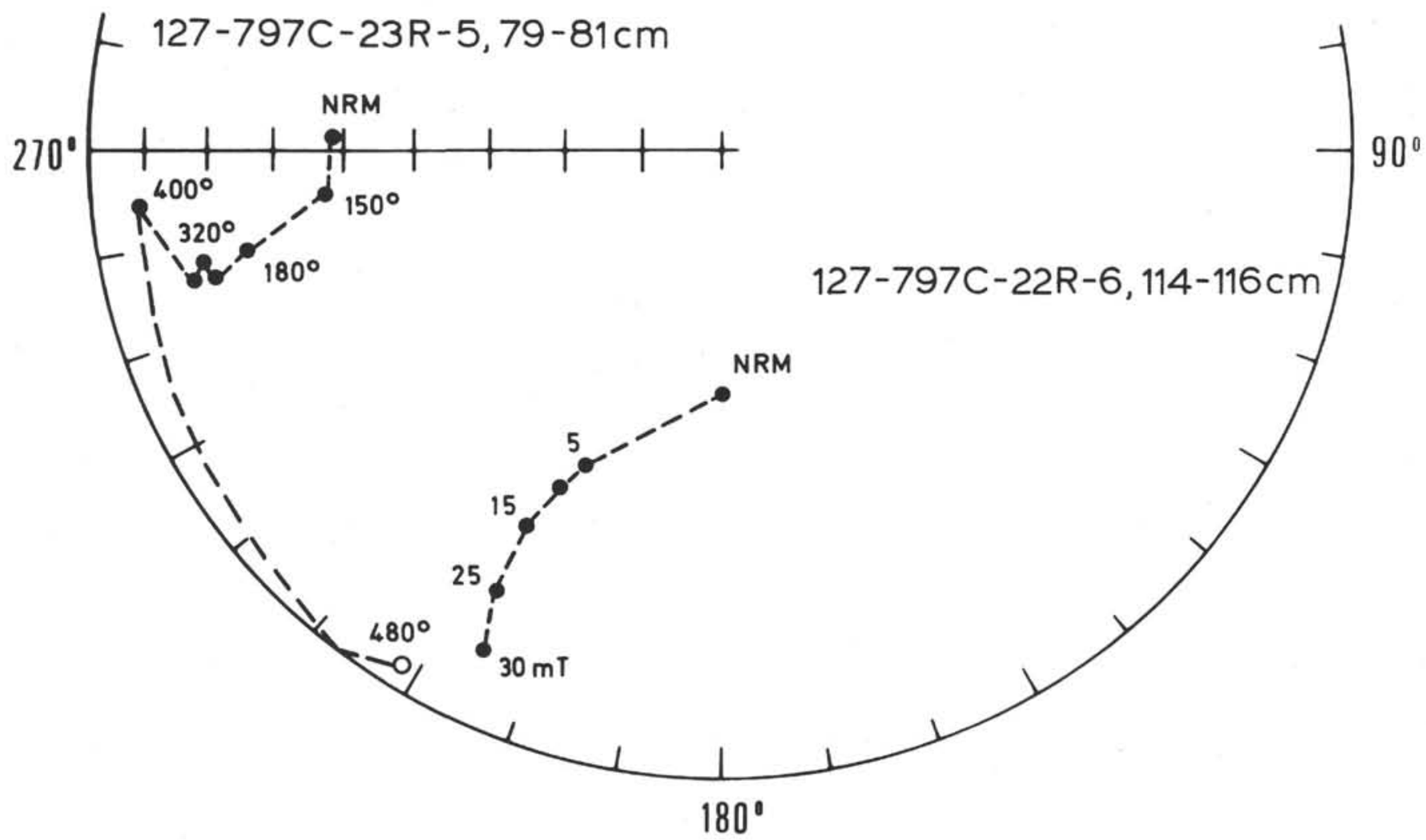

Figure 7. Change of magnetic directions of sedimentary rocks interlayered with the basalts during thermal and AF demagnetization. A stable end-point is not reached. Open symbols: negative inclinations; solid symbols: positive inclinations. 


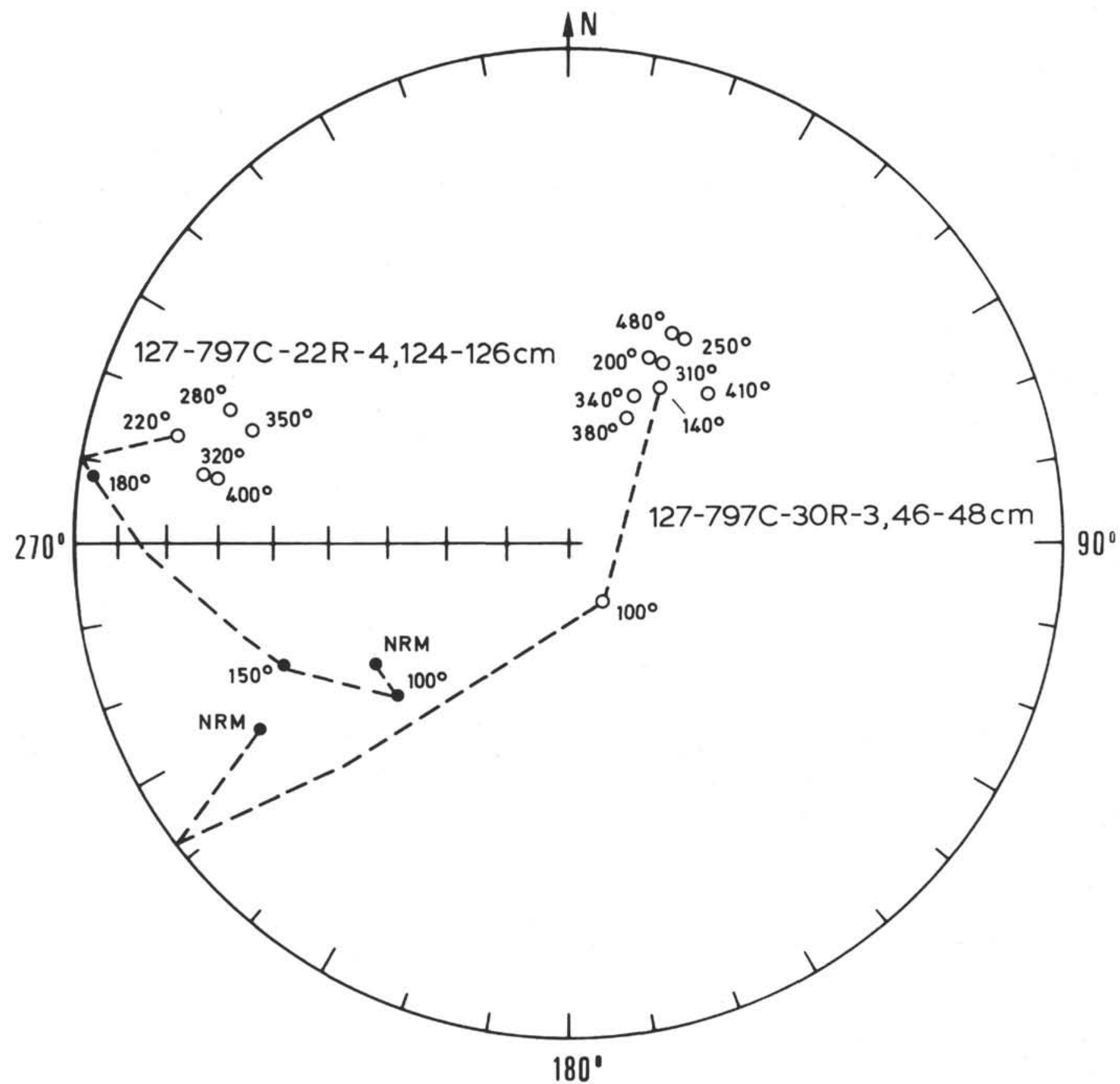

Figure 8. Examples of magnetic directions reaching a stable end-point during progressive thermal demagnetization from sediments interlayered with the basalts. Open symbols: negative inclinations; solid symbols: positive inclinations.

\section{VISCOUS REMANENT MAGNETIZATION EXPERIMENT}

It is well known that oceanic basalts are sometimes very susceptible to acquiring a viscous remanent magnetization (VRM), and for this reason Lowrie (1973) proposed that this kind of magnetization might be an important magnetization component of the oceanic crust. Many experiments have been carried out to estimate the seriousness of VRM on the oceanic basalt magnetization. However, most of these experiments were carried out after the NRM was completely destroyed by AF-demagnetization and on a selected number of specimens which showed instability during measurement of NRM properties. More- over, the VRM was given to the samples in a field of $0.1 \mathrm{mT}$. These experiments therefore tried to establish the behavior of the VRM, but in artificial conditions. Lowrie and Kent $(1976,1978)$ and Tivey and Johnson (1981) found that VRM acquired in the presence of NRM is more serious than after AF demagnetization.

In order to apply the VRM acquisition to the basement of the Japan Sea, the present experiment was carried out on the whole collection of samples and under conditions similar to those existing in nature. The results, relative to Sites 794, 795, and 797 are reported in Tables 1, 2 , and 3 , respectively. The VRM was calculated by subtracting the original NRM values from the remanence measured after $1376 \mathrm{hr}$. This VRM was used to calculate the ratio VRM/NRM\% which is an 

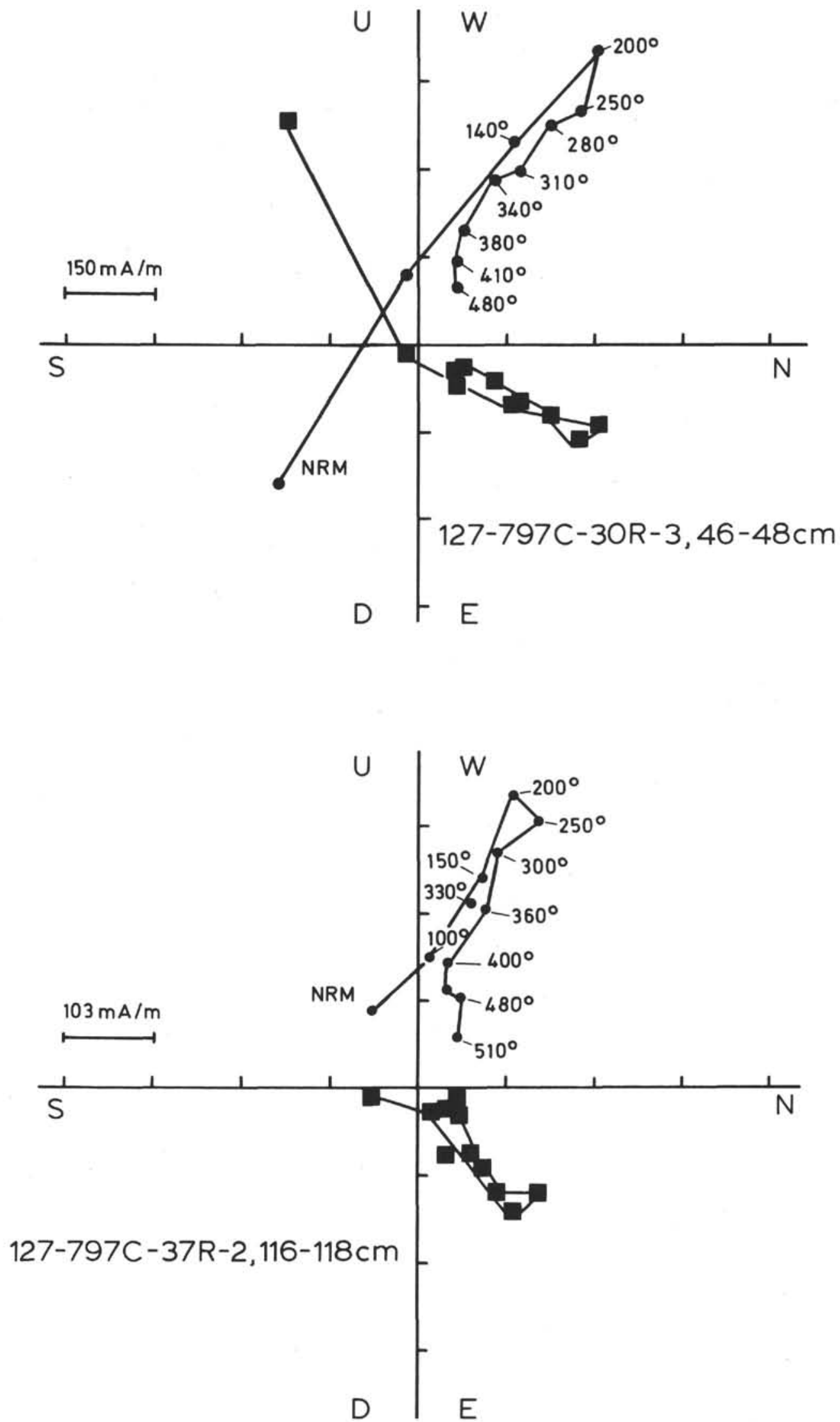

Figure 9. Examples of vectors demagnetization diagrams showing two opposite components with different unblocking temperatures. 1 division: $15 \mathrm{~mA} / \mathrm{m}$ for the upper sample, and $10.3 \mathrm{~mA} / \mathrm{m}$ for the lower sample. 
expression of the seriousness of the VRM. After the VRM acquisition experiment (lasting $1376 \mathrm{hr}$ ), a select number of samples were stored in a magnetic shield for $7176 \mathrm{hr}$ to observe the decay of the VRM.

The VRM acquisition of the basalts recovered from the sills of the acoustic basement of the Yamato Basin (Sites 794 and 797) was higher (mean value for the ratio VRM/NRM\% respectively of $46.9 \%$ and $54.9 \%$ ) than that exhibited by the basalts from Site 795 in the Japan Basin, which had only $20 \%$ of viscosity. Lowrie and Kent (1978) reported a mean value for the VRM/NRM\% measured after AF demagnetization of 111 samples from 30 DSDP sites of only $20 \%$. A comparison of these results confirm that the VRM acquired in the presence of the NRM is much more serious than the VRM acquired from a demagnetized state.

Whether the VRM is acquired by multidomain or by very fine, near superparamagnetics grains, according to theory, the growth must be logarithmic with time (Dunlop 1973). However, as observed in several oceanic basalts (Lowrie, 1974; Lowrie and Kent, 1978), the VRM was acquired by a multistage process. Two or three stage were observed during our experiments. About $50 \%$ of the samples exhibited a three-stage process (Fig. 10), and some results seem to suggest that in the samples showing two stages, the third was not observed because the length of the experiment was not sufficient to reveal it. The basalts which exhibited a three-stage process had, after only $1376 \mathrm{hr}$, a VRM of the same magnitude of the NRM; two samples (127-794C-4R-1, 79-81 cm; and 127-797C-44R-1, 33-35 cm) exceed this value by 3 and 5 times, respectively (Fig. 11). Samples from the lower unit of Site 795 exhibited low viscosity with a slow, but constant, increase of VRM with time (Fig. 12). Few specimens decreased the NRM probably because the VRM grew in the opposite direction of the magnetization vector.

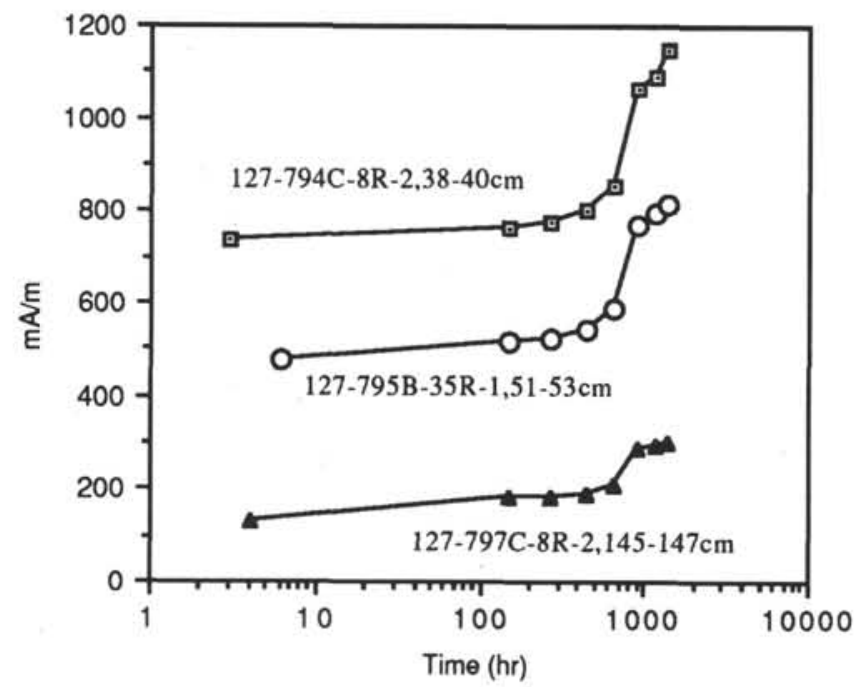

Figure 10. Examples of three-stage acquisition of viscous remanent magnetization from basaltic rocks.

Experimental observations about acquisition and decay of VRM indicate contrasting results. Several authors found that the initial rate of decay of VRM is the same as the initial rate of acquisition (see Dunlop, 1973, for a complete list of references), however, more recent studies suggest that VRM decay proceeds more slowly than the corresponding VRM acquisition (Dunlop, 1983; Tivey and Johnson 1984) with the viscous acquisition coefficient (Sa) about twice the viscous decay coefficient $(\mathrm{Sd})(\mathrm{Sa}=2 \mathrm{Sd})$. The experiments carried out on the basalts from the Japan Sea for this study indicate that the VRM decay curves do not follow the VRM acquisition curves, and any correlation between the two curves appears impossible. VRM

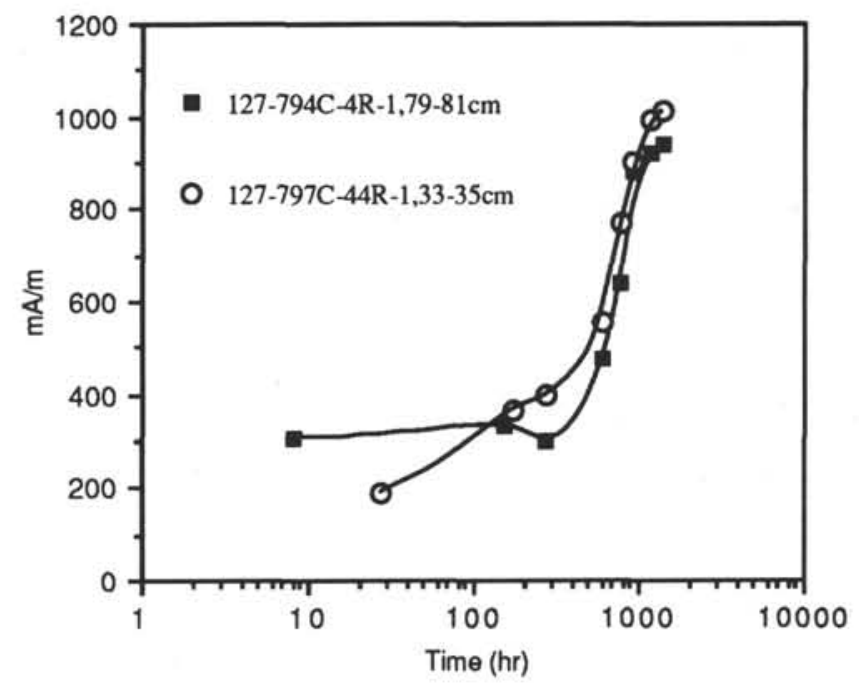

Figure 11. Examples of very viscous samples which acquired VRM exceeding the NRM after $1370 \mathrm{hr}$ under the present magnetic field.

decay appears more constant with time with respect to the VRM acquisition (Figs. 13 and 14). After $7176 \mathrm{hr}$ of storage in a magnetic shield (more than $1 \mathrm{yr}$ ) VRM decayed below $50 \%$ of the NRM in very few samples. The behavior was variable from sample to sample, and it is difficult to establish a common trend. Some samples increased in intensity, and this could be related to the erasing of a VRM with a direction opposite to the magnetization vector. An example of this processes is reported in Figure 15 showing the change of the NRM direction during VRM acquisition and decay. Some samples, after an initial decay of the remanence, changed, acquiring VRM. The basalts from the lower unit of Site 795 were stable, and the VRM changed only of few percent with very consistent paleomagnetic directions.

\section{DISCUSSION AND SUMMARY}

The results of the magnetic properties measured from the igneous rocks recovered in the Japan Sea indicate differences between the basalts of the acoustic basement of the Yamato Basin (Sites 794 and 797) and the Japan Basin (Site 795). The former are characterized by

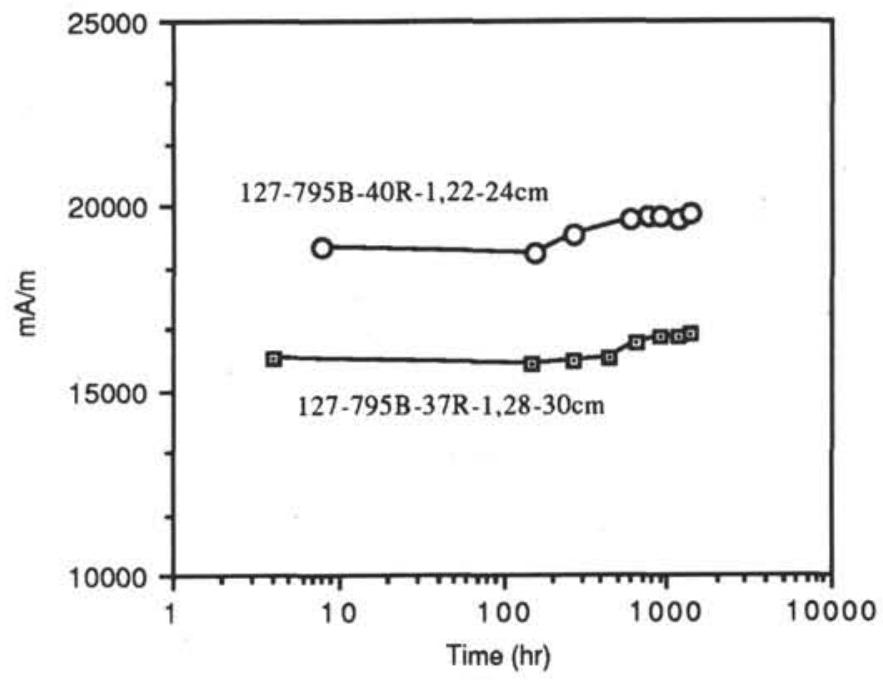

Figure 12. Examples of VRM acquisition from two samples collected at Site 795 . 


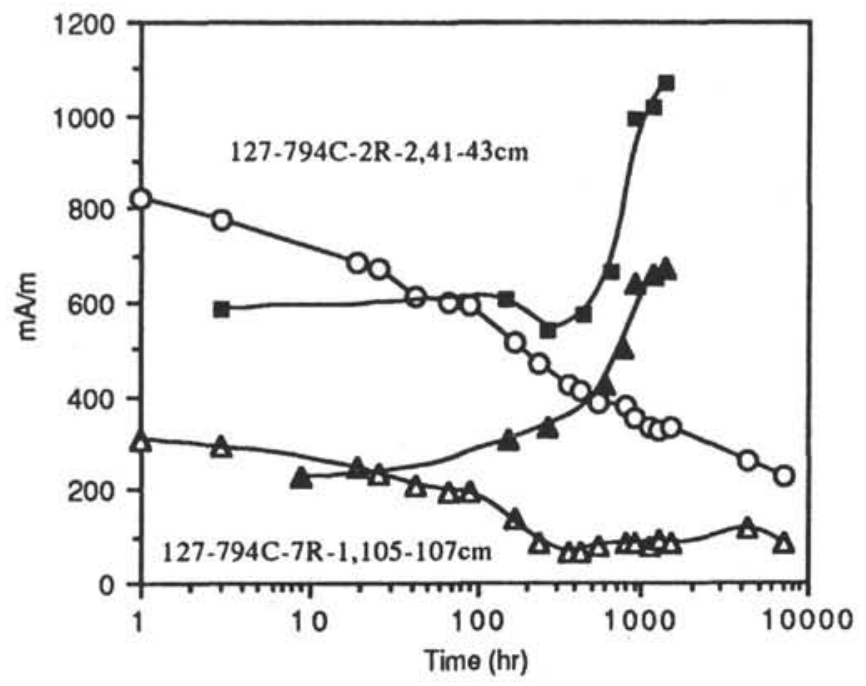

Figure 13. Comparison between the curves of VRM acquisition (solid symbols) and VRM decay (open symbols) from basalts recovered from Site 794.

higher values of magnetic susceptibility while the NRM intensity is about one order of magnitude less with respect to the samples measured at Site 795. The Koenigsberger (Q) ratios are probably one of the most significant differences between the two basins. In the Yamato Basin low $Q$ values testify that the remanence does not dominant over the induced magnetization, so one of the requirements of the Vine and Matthews (1963) hypothesis to produce symmetrical oceanic magnetic anomalies over ridges is not present in the Yamato Basin. This is the reason for the unclear magnetic anomaly pattern observed in this basin. On the contrast, in the Japan Basin, remanence dominates over the induced magnetization and a marine magnetic anomaly pattern can be recognized (Tamaki and Kobayashi 1988). Q values around unity as observed at Sites 794 and 797 and in the upper unit at Site 795, together with the high VRM of these rocks, testify to large grain size in the multidomain range for the carrier of the remanence. Optical observations confirm this statement and support Irving's (1970) assumption that conditions at initial rifting would favor development of coarse grain sizes in basalts.

The frequency dependence susceptibility $\mathrm{X}_{\mathrm{fd}}$ should exhibit a decrease with frequency according to the Neel's (1955) theory of magnetic viscosity. Before the measurements reported in this paper, $\mathrm{X}_{\mathrm{fd}}$ measurements on oceanic basalts were carried out only by a recent study of Trigui and Tabbagh (1990). The mean decrease in susceptibility observed in the basalts drilled from the Japan Sea is in the range $1.09 \%-1.99 \%$ which is lower than the theoretical decrease of $4 \%$ calculated by Vincenz (1965) for multidomain grains and a tenfold increase in frequency.

Ellwood's emplacement parameter (F) was unsuccessfully applied to the basalts in this study. At Site 794 where all the units have been recognized as sills, only two samples exhibited an AMS representative of an intrusive emplacement $(F>1.040)$. Also at Site 797, parameter $\mathrm{F}$ does not show a correlation with the recognized emplacement mode of the basalts. One of the reasons for the inapplicability of this criterion is that it has been applied to relatively younger (and less altered) basalts (Ellwood, 1978). However, some debate could exist about the emplacement mode of the first basaltic unit at Site 797 which has been considered a lava flow. One sample from this unit exhibited a F value of 1.044 typical for intrusive rock. As found by Ellwood (1975), intrusive rocks show a wide range of distribution of $\mathrm{F}$ values, but extrusive rocks are much more characterized by $\mathrm{F}$ values close to one. On this basis it is possible that Unit 1 at Site 797 also is a
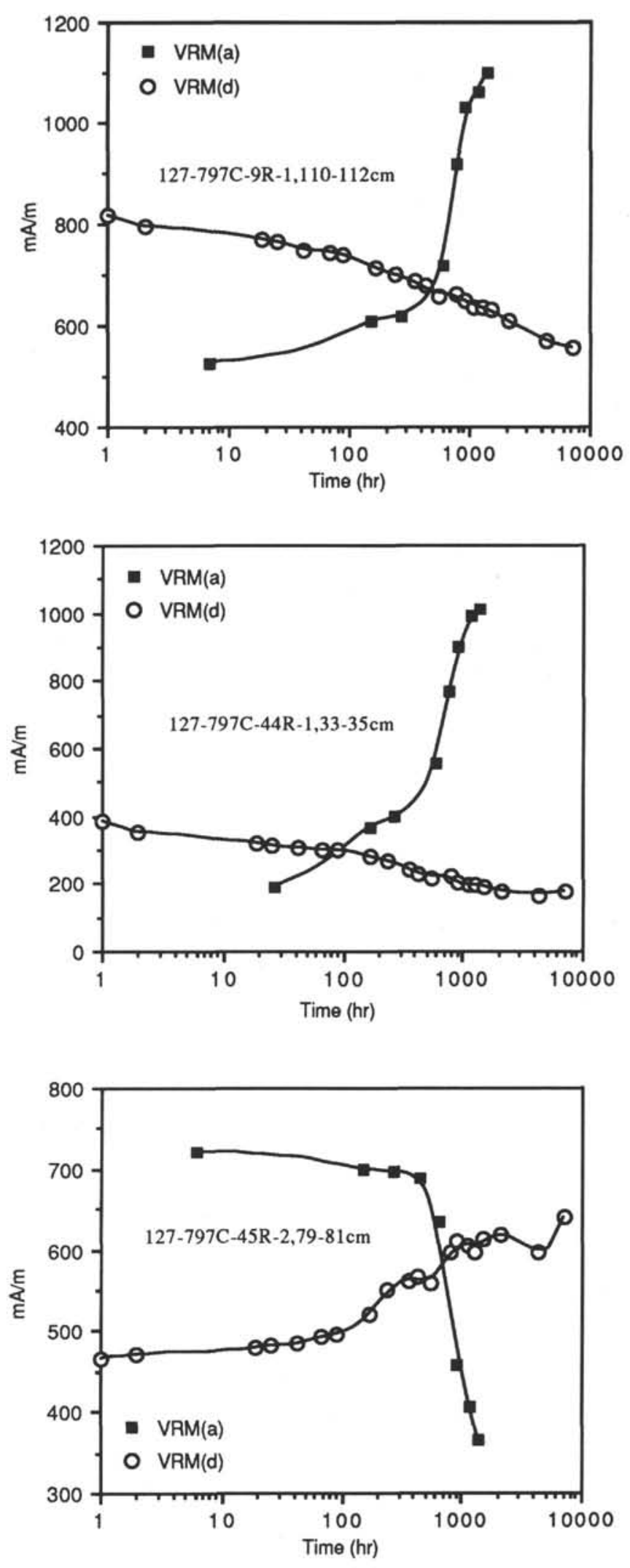

Figure 14. Comparison between the curves of VRM acquisition and VRM decay from basalts recovered from Site 797. 
dike. Petrographic similarity with Unit 2 suggests a similar emplacement mode for this unit, and probably only intrusive rocks characterize the acoustic basement of the Yamato Basin. F values from Site 795 are well in the range of the extrusive emplacement mode supporting the observation that the basalts recovered at this site represent lava flows.

Igneous rocks from Site 795 exhibit only normal polarities while both polarities were observed in the dikes from Sites 794 and 797 testifying to different ages for the emplacement of these rocks. Especially at Site 794 the emplacement history of the dikes appears complicated with normal polarity at the top and the bottom of the section, while in the center negative inclinations predominate, but with a normal polarity in the lower part of Core 127-794C-3R. The inclinations of the basalts recovered with the upper eleven cores at Hole 794C are systematically shallower than the expected value and only the last two cores, which also had a different polarity, exhibited inclinations consistent with the latitude of the site. Three possibilities can explain these results:

1. The basement is disrupted only in the upper $90 \mathrm{~m}$.

2. The basalts at the bottom of the hole have a different age, possibly younger, and were emplaced after the disruption.

3 . The basalts recovered with the upper eleven cores were emplaced in a short period of time and their directions represent a virtual geomagnetic pole (VGP) which was characterized by shallow inclinations.

Against this latter hypothesis, play the differences observed in the magnetic properties which could indicate that the emplacement was not a single event as expected in the case of a not-averaged VGP.

The intrusion of the dikes clearly affected the magnetization of the interlayered sediments as testified by the process of remagnetizations observed at Site 797. The presence of two opposite components of magnetization with different unblocking temperatures, gives an opportunity to estimate the temperature at which the sediments were heated. The separation of these two components show that unblocking temperatures are restricted to $200^{\circ}-220^{\circ} \mathrm{C}$ and in few case reached $250^{\circ} \mathrm{C}$ (Fig. 9). These temperatures can be considered representative of the heating of the sandstones and siltstones interlayered with the igneous rocks.

Viscous remanent magnetization (VRM) experiments showed that the VRM acquisition occurs in two or three different stages, each of which following a logarithmic dependence respect to the acquisition time (Fig. 10). VRM decay is a slower process, but still involving more than one stage (Figs. 13 and 14). The VRM observed in the studied samples was significantly higher than the VRM reported from other study on demagnetized samples, supporting the observation of Lowrie and Kent (1978) that VRM is more serious in undemagnetized samples.

\section{ACKNOWLEDGMENTS}

The author is grateful to Dr. L. Monti for the help in measuring the VRM of the rocks and to Dr. C. Ferretti for plotting the data. This paper was supported by Contribution No. 826 of the Istituto di Geologia Marina, CNR, Bologna, Italy.

\section{REFERENCES}

Dunlop, D. J., 1973. Theory of the magnetic viscosity of lunar and terrestrial rocks. Rev. Geophys. Space Phys., 11:855-901.

1983. Viscous magnetization of $0.04-100 \mu \mathrm{m}$ magnetites. Geophys. J. R. Astron. Soc., 74:667-687.

Ellwood, B. B., 1975. Analysis of emplacement mode in basalt from Deep-Sea Drilling Project Holes 319A and 321 using anisotropy of magnetic susceptibility. J. Geophys. Res., 80:4805-4808.

1978. Flow and emplacement direction determined for selected basaltic bodies using magnetic susceptibility anisotropy measurements. Earth Planet. Sci. Lett., 41:254-264.

Irving, E., 1970. The mid-Atlantic ridge at $45^{\circ} \mathrm{N}$ : XIV. Oxidation and magnetic properties of basalt: review and discussion. Can. J. Earth. Sci., 7:1528-1538.

Lowrie, W., 1973. Viscous remanent magnetization in ocean basalt. Nature. 243:27-30.

, 1974. Ocean basalt magnetic properties and the Vine and Matthews hypothesis. J. Geophys., 40:513-563.

Lowrie, W., and Kent, D. V., 1976. Viscous remanent magnetization in basalt samples. In Yeats, R. S., Hart, S. R., et al., Init. Repts. DSDP, 34: Washington (U.S. Govt. Printing Office), 479-484.

1978. Characteristics of VRM in ocean basalts. J. Geophys., 44:297-315

Neel, L., 1955. Some theoretical aspects of rock magnetism. Advan. Phys. (Phys. Mag. Suppl.), 4:191-243.

Tamaki, K., and Kobayashi, K., 1988. Geomagnetic anomaly lineation in the Japan Sea. Mar. Sci. Mon., 20:705-710.

Tamaki, K., Pisciotto, K., Allan, J., et al., 1990. Proc. ODP, Init. Repts., 127: College Station, TX (Ocean Drilling Program).

Tivey, M., and Johnson, H. P., 1981. Characterization of viscous remanent magnetization in single- and multi-domain magnetite grain. Geophys. Res. Lett., 8:217-220.

1984. The characterization of viscous remanent magnetization in large and small magnetite particles. J. Geophys. Res., 89:543-552.

Trigui, M., and Tabbagh, A., 1990. Magnetic susceptibility of ocean basalts in alternative fields. J. Geomagn. Geoelectr, 42:621-636.

Vincenz, S. A., 1965. Frequency dependence of magnetic susceptibility of rocks in weak alternating fields. J. Geophys. Res., 70:1371-1377.

Vine, F. J., and Matthews, D. H., 1963. Magnetic anomalies over ocean ridges. Nature, 199:947-949.

Date of initial receipt: 23 April 1991

Date of acceptance: 10 February 1992

Ms 127/128B-212 


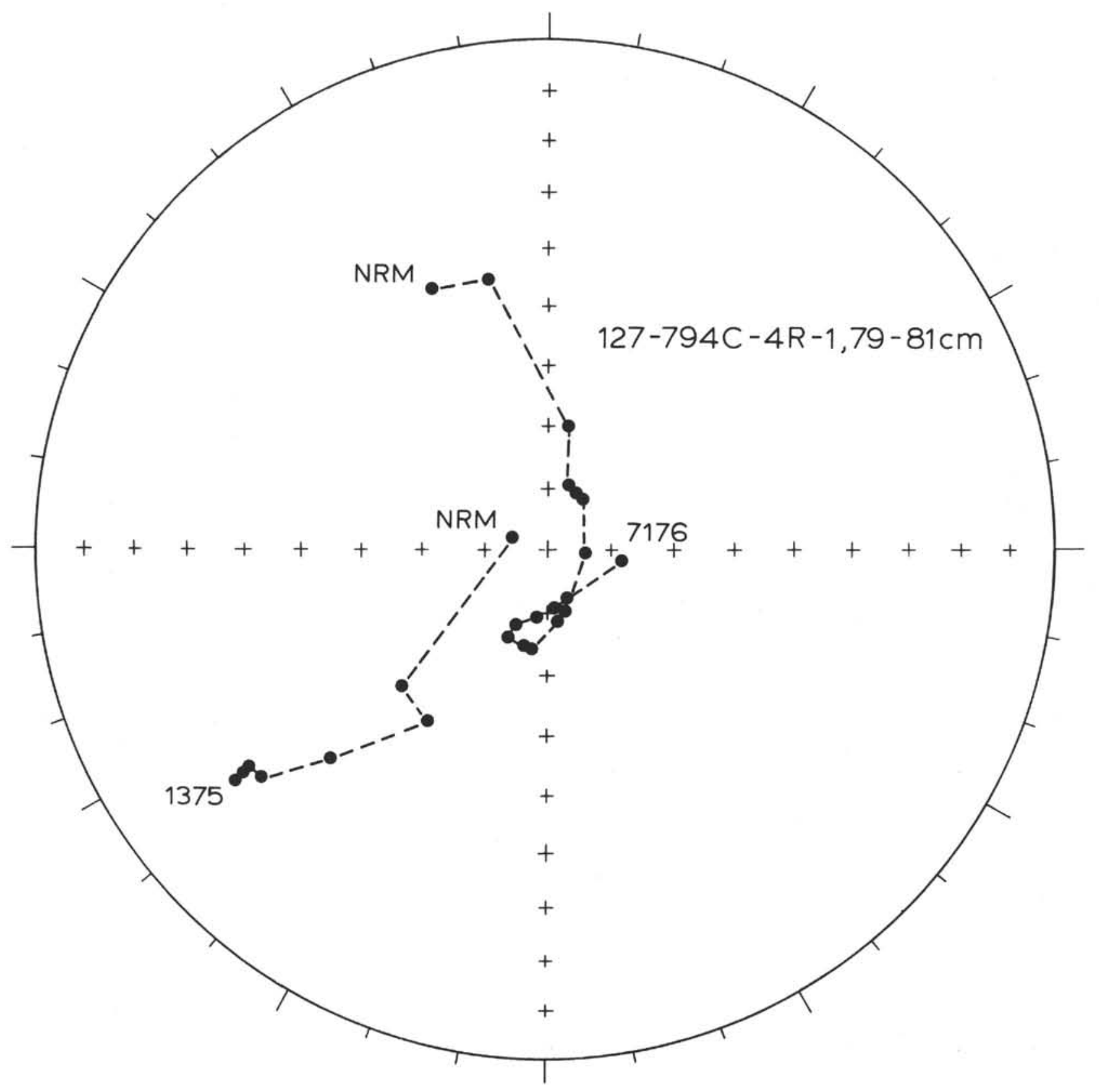

Figure 15. Stereonet plot of paleomagnetic directions changing with time (numbers express hours) during acquisition and decay of VRM. 


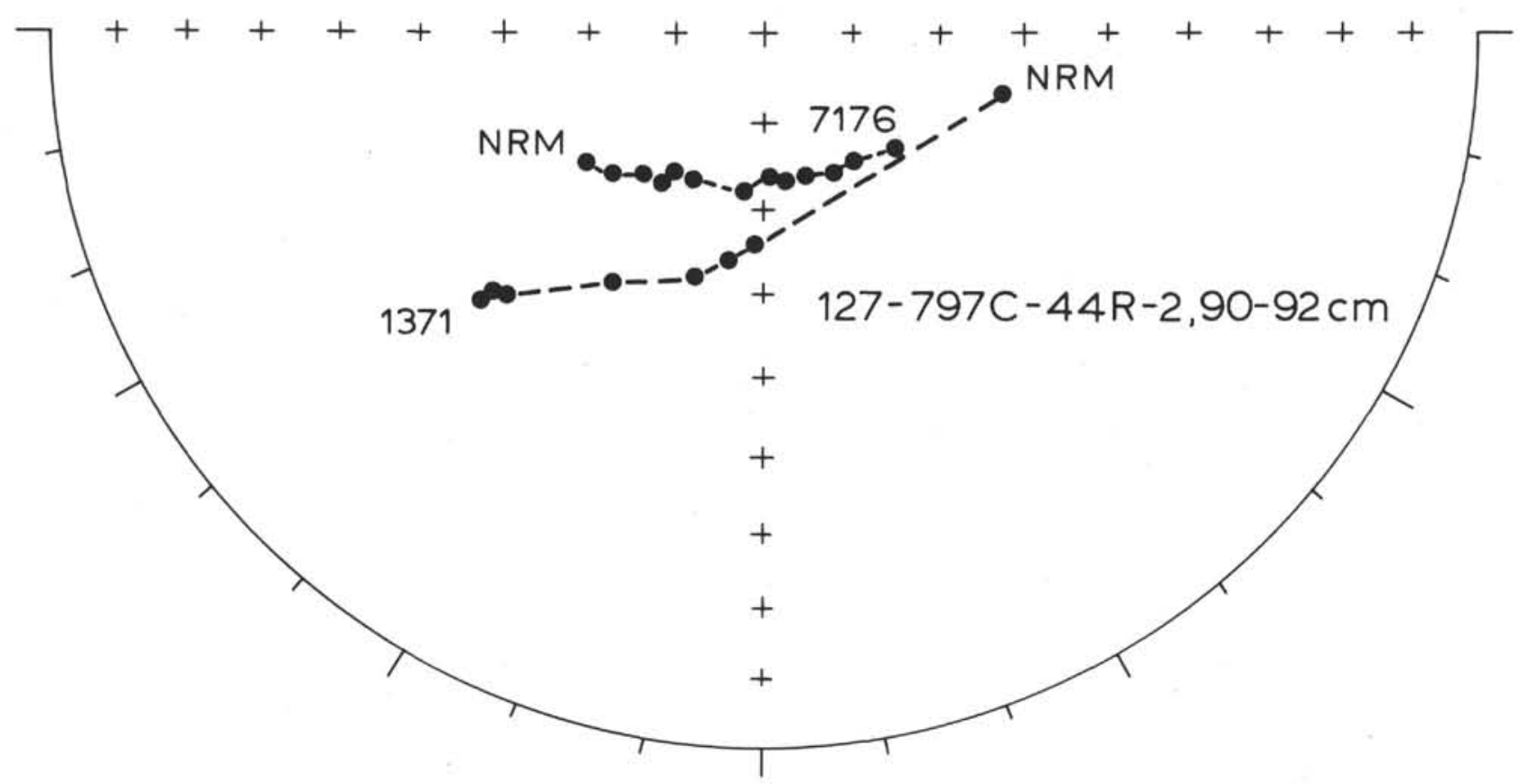

Figure 15 (continued). 